\title{
INFLUÊNCIA DO RESÍDUO DE PRODUÇÃO DE CERVEJA NO CRESCIMENTO DE FUNGOS Ganoderma E NA OBTENÇÃO DE $\beta$ - GLUCANAS
}

\author{
Djonice Beatriz Doege Schipmann'1, Thaynã Gonçalves Timm², Tania Maria \\ Costa $^{3}$ e Lorena Benathar Ballod Tavares ${ }^{4}$
}

\begin{abstract}
Resumo: $A$ utilização de efluentes do setor cervejeiro como substrato em cultivos fúngicos torna-se uma alternativa sustentável de reaproveitamento de resíduos. Este trabalho avaliou a velocidade de crescimento micelial radial $\left(V_{m}\right)$ e a produção de $\beta$-glucanas pelos fungos Ganoderma lipsiense e Ganoderma applanatum cultivados em placas de Petri contendo resíduo da centrifugação da cerveja Pilsen (RCP), previamente caracterizado quimicamente, nas concentrações bruta (T1), diluído 50\% (T2) e 75\% (T3), com medições radiais diárias durante 13 dias. Ao término deste período, os micélios foram removidos realizando-se posterior secagem $\left(55^{\circ} \mathrm{C}\right)$ para quantificação de $\beta$-glucanas. A caracterização química do resíduo indicou a presença de fósforo (81,20 mg L $\left.\mathrm{L}^{-1}\right)$, nitrogênio amoniacal $\left(9,18 \mathrm{mg} \mathrm{L}^{-1}\right)$, além de $D B O\left(17.750,00 \mathrm{mg} \mathrm{O}_{2} \mathrm{~L}^{-1}\right)$ e $D Q O$ (32.050,00 mg O $\mathrm{L}^{-1}$ ). Todas as concentrações de resíduo proporcionaram crescimento micelial e produção de $\beta$-glucanas. Em T1, foram obtidos maiores $V_{m}(4,48$ e 3,90 mm dia-1) para G. applanatum e G. lipsiense. Em relação as $\beta$-glucanas, G. lipsiense apresentou maiores teores (32 \%) no T2 e 30,28\% no T1, enquanto G. applanatum produziu teores abaixo de $20 \%$. Os resultados mostram a influência da concentração do meio de cultivo e da espécie fúngica na produção de biocompostos e sugerem que o RCP estudado pode ser reaproveitado, sendo empregado como substrato para produção de compostos de interesse farmacêutico, tais como $\beta$-glucanas.
\end{abstract}

Palavras-chave: Fungos basidiomicetos. $\beta$-glucanas. Indústria cervejeira.

\section{Introdução}

Problemas ambientais ocasionados pela disposição inadequada de resíduos industriais têm despertado grande interesse nos últimos anos. Um dos impactos negativos da disposição inadequada destes resíduos está relacionado com a contaminação de mananciais e das águas subterrâneas, o que acarreta sérios danos em relação à oferta $\mathrm{e}$ demanda de água (DI BERNARDO, 2000). A fim de minimizar os elevados custos associados à disposição adequada dos resíduos industriais, pesquisas tecnológicas envolvendo a utilização, tratamento e disposição destes resíduos têm se mostrado promissoras (CHICATTO et al., 2014, PEDRI, 2014, WISNIEWSKI et al., 2010).

Durante o processamento da cerveja, há uma grande produção de resíduos líquidos, no qual a demanda bioquímica de oxigênio excede os padrões legais, gerando assim altos volumes de efluentes industriais (FERREIRA et al., 2011). O lançamento deste efluente industrial nos corpos hídricos tornaos cada vez mais eutrofizados e poluídos (MACEDO; SIPAÚBA-TAVARES, 2010), acarretando numa redução na disponibilidade desse recurso natural. $\mathrm{O}$ aproveitamento deste resíduo pode resultar em redução do impacto ambiental negativo, caso este não seja devidamente tratado ou disposto.

Resíduos industriais utilizados como nutrientes em processos biotecnológicos para obtenção de compostos naturais bioativos têm sido empregados há muitos anos (COSTA; TAVARES; OLIVEIRA, 2016). Tal possibilidade decorre da capacidade dos fungos em colonizar diferentes tipos de substratos (COSTA et al., 2017), contendo macro e micronutrientes. Na obtenção de produtos naturais, especialmente em pesquisas voltadas à descoberta de novos fármacos, tem-se empregado distintos

\footnotetext{
1E-mail: djonice_doege@yahoo.com.br

FURB - Universidade Regional de Blumenau. PPGEA - Programa de Pós-Graduação em Engenharia Ambiental. CAMPUS II - Complexo Tecnológico. Rua São Paulo, 3250 - Itoupava Seca CEP 89.030-000 - BLUMENAU - SC, Brasil

2E-mail: ttimm@furb.br

${ }^{3}$ E-mail: tmcosta02@gmail.com

${ }^{4}$ E-mail: lorena@furb.br
} 
microrganismos, os quais são considerados verdadeiras biofábricas (SOUZA et al., 2016, MATOS LINS et al., 2018). Os fungos basidiomicetos mostram ampla capacidade de desenvolvimento em substratos sólidos (ZENNI; HELM; TAVARES, 2018) e líquidos (LENZI et al., 2018), podendo gerar produtos de interesse à indústria de alimentos, fármacos e cosméticos (BENTO; CASARIL, 2012).

Fungos do gênero Ganoderma, tais como G. lucidum, G. applanatum, G. tsugae, G. lingzhi, G. sinense e G. capense, são caracterizados como potenciais organismos produtores de importantes compostos com propriedades biológicas e terapêuticas. No entanto, poucos estudos destacam o potencial da espécie $G$. lipsiense. Recentemente, uma pesquisa realizada com G. lipsiense demonstrou sua capacidade em produzir compostos fenólicos, tais como o ácido cafeico e ácido siríngico (COSTA, 2019). Outra propriedade terapêutica observada no gênero Ganoderma é a atividade antimicrobiana. Para o fungo $G$. lipsiense, atividade antibacteriana foi observada contra três organismos patogênicos (Escherichia coli, Pseudomonas aeruginosa e Staphylococcus aureus) (COSTA, 2019), bem como para Vibrio cholerae (MTCC 3904) (SINGDEVSACHAN et al. 2017).

Devido a sua natureza química, resíduos líquidos oriundos do processo de produção de cerveja podem ser considerados substratos promissores para fungos basidiomicetos. Tais resíduos podem ser utilizados como meios de cultivo por fungos para a síntese de compostos bioativos de importância farmacêutica, como os polissacarídeos $\quad \beta$-glucanas. Este polissacarídeo pode atuar no sistema imune, no qual atribuem-se propriedades antitumorais, antivirais, antibacterianos e antiinflamatórios (SARI et al., 2017). Para a obtenção desses polissacarídeos, se faz necessário o uso de meios de cultivo com concentrações adequadas de fontes de carbono e nitrogênio.

Neste contexto, o objetivo deste estudo foi avaliar o potencial do resíduo da centrifugação da cerveja Pilsen $(R C P)$ de uma cervejaria de Blumenau (Blumenau, SC, Brasil), como substrato para o crescimento micelial radial de dois fungos do gênero Ganoderma e sua capacidade de produzir $\beta$ glucanas.

\section{Metodologia}

O resíduo utilizado neste estudo como substrato, foi coletado numa empresa de produção de cerveja, após o término do processo de centrifugação da cerveja Pilsen. Uma amostra do resíduo do processo de centrifugação da cerveja Pilsen $(R C P)$ foi enviada para análises de caracterização química no Laboratório de Análises de Águas e Efluentes do SENAI (LANAE, Blumenau/SC) e o restante foi armazenado à $4^{\circ} \mathrm{C}$ para posterior utilização no cultivo em placas.

\subsection{Determinação de parâmetros físico- químicos}

A caracterização química do resíduo quanto aos teores de nitrato, nitrito, nitrogênio amoniacal, fósforo total, DBO e DQO foi realizada seguindo a metodologia padrão publicada no Standard Methods for the Examination of Water and Wastewater (APHA, 2012). Estes micronutrientes foram quantificados com intuito de verificar o potencial do meio para o crescimento fúngico.

\subsection{Fungos, manutenção e meio de cultivo}

Os fungos $G$. lipsiense (CCIBt 2689) e G. applanatum (CCIBt 2978), adquiridos do Instituto de Botânica (São Paulo, Brasil) foram cultivados em placas contendo extrato de malte esterilizado $(1 \% \mathrm{~m} / \mathrm{v}) \mathrm{Kasvi}^{\circledR}$, peptona bacteriológica $(0,1 \% \mathrm{~m} / \mathrm{v}) \mathrm{Kasvi}^{\circledR}$ e batatadextrose ágar (BDA - 3,9\% m/v) Himedia ${ }^{\circledR}$ por 28 dias de incubação a $28{ }^{\circ} \mathrm{C}$ e posteriormente armazenados a $4{ }^{\circ} \mathrm{C}$ com repiques periódicos a cada 3 meses.

\subsection{Determinação da velocidade de crescimento micelial radial}

Os ensaios de crescimento micelial foram realizados em placas de Petri previamente preparadas com meio de cultivo sólido contendo $R C P$ em quatro tratamentos distintos: tratamento controle (TC) contendo somente meio sintético BDA $(3,9 \% \mathrm{~m} / \mathrm{v})$ Himedia $^{\circledR}$; tratamento 1 (T1) contendo meio $\operatorname{BDA}(1,5 \% \mathrm{~m} / \mathrm{v})$ e $R C P$ bruto; tratamento 2 (T2) contendo meio BDA $(1,5 \% \mathrm{~m} / \mathrm{v})$ e $R C P$ diluído $50 \%$ em água destilada (50:50); tratamento 3 (T3) contendo meio BDA (1,5\% $\mathrm{m} / \mathrm{v}$ ) e $R C P$ diluído $75 \%$ em água destilada 
(25:75). Os meios de cultivo foram esterilizados em autoclave a $121^{\circ} \mathrm{C}$ por 15 minutos.

$O$ crescimento micelial radial de $G$. lipsiense e $G$. applanatum sobre $R C P$ foi avaliado em placas de Petri empregando os métodos adaptados descritos por Wheeler, Hurdman e Pitt (1991) e Laszlo e Silman (1993). Um disco de micélio de $7 \mathrm{~mm}$ de cada fungo foi inserido no centro da placa de Petri contendo o meio de cultivo e incubado em estufa de crescimento a $27 \pm 2^{\circ} \mathrm{C}$ por 13 dias. Os ensaios foram realizados em cinco replicatas para cada fungo e tratamento. $\mathrm{O}$ crescimento micelial radial foi mensurado utilizando um paquímetro e registro fotográfico, e medindo-se o diâmetro em duas posições perpendiculares obtendo, deste modo, o raio médio das colônias para cada 24 horas.

O valor da velocidade média de crescimento micelial radial foi determinada para cada fungo de acordo com a Equação 1.

$$
V_{m}=\frac{R_{f}-R_{i}}{\Delta t}
$$

Onde:

$V_{m}=$ velocidade média de crescimento diário (mm dia-1);

$R_{f}=$ raio final da colônia $(\mathrm{mm})$;

$R_{i}=$ raio inicial da colônia $(\mathrm{mm})$;

$\Delta t=$ variação do tempo (dias).

A taxa de crescimento foi determinada para cada fungo de acordo com a equação 2 da velocidade específica de crescimento.

$$
\mu(t)=\frac{1}{D} \frac{d D}{d t}
$$

Onde:

$\mu(t)=$ taxa de crescimento específico $\left(\mathrm{h}^{-1}\right)$; $t=$ tempo $(\mathrm{h})$

$D=$ diâmetro da colônia $(\mathrm{mm})$.

Os cálculos para determinação dos valores da velocidade média e da taxa de crescimento fúngico foram realizados utilizando Microsoft Excel ${ }^{\circledR}$.

\subsection{Determinação do teor de $\beta$-glucanas}

Ao final do período de incubação, foi realizado a remoção do micélio desenvolvido sobre o ágar por meio de raspagem manual. Em seguida, os micélios foram transferidos para uma placa de Petri no qual foram desidratados $\left(55^{\circ} \mathrm{C}\right.$ por 2 horas) de acordo com Timm et al. (2019) em estufa com secagem convectiva (Tecnal TE-324/1) e triturados em liquidificador laboratorial, de forma a obter um pó. Posteriormente, o teor de $\beta$-glucanas foi dosado utilizando um kit comercial K-YGLU/Megazyme, seguindo-se o protocolo conforme o fabricante (Megazyme ${ }^{\circledR}$; IDA Business Park, Bray, Wicklow, Ireland). Por meio deste kit obteve-se a determinação dos valores de glucanas totais e a-glucanas, medindo as absorbâncias de todas as soluções resultantes do protocolo dos ensaios a $510 \mathrm{~nm}$ em espectrofotômetro (SHIMADZU UV-Vis-1650 PC), em relação ao branco do reagente. $O$ teor de $\beta$-glucanas foi calculado empregando as equações para glucanas totais (Equação 3), a-glucanas (Equação 4) e $\beta$-glucanas (Equação 5) e o resultado expresso em percentual (\%), g / $100 \mathrm{~g}$ de amostra seca.

$$
\begin{aligned}
& \text { Glucanas totais (\%) }=\Delta \mathrm{E} * \frac{\mathrm{F}}{\mathrm{W}} * 90 \\
& \text { a-glucanas (\%) }=\Delta \mathrm{E} * \frac{\mathrm{F}}{\mathrm{W}} * 9,27 \\
& \beta \text {-glucanas }(\%)=(\text { Gluc. totais }) \text { - (a-gluc.) }
\end{aligned}
$$

Onde:

$\Delta \mathrm{E}=$ absorbância amostra - absorbância branco.

$\mathrm{F}=$ Fator de conversão para $\mu \mathrm{g}$ de D-glucose = 100/absorbância padrão.

$\mathrm{W}=$ massa da amostra utilizada.

Fator de correção de volume $=90$ e 9,27

Gluc. = glucanas

\subsection{Determinação dos valores de $\mathrm{pH}$}

$\mathrm{O} \mathrm{pH}$ inicial e final do meio de cultivo foi avaliado em triplicata, utilizando o método potenciométrico com um pHmetro (Tecnal) previamente calibrado. $\mathrm{O}$ meio de cultivo foi macerado com auxílio de um bastão de vidro e em seguida, pesado 1 grama de amostra em tubo de ensaio e acrescido de $10 \mathrm{~mL}$ de água destilada. A amostra foi homogeneizada com o auxílio de um vórtex mixer e após 10 minutos de repouso foi realizada a determinação do valor do $\mathrm{pH}$ no sobrenadante por medida direta (INSTITUTO ADOLFO LUTZ, 2005).

\subsection{Análise estatística}

Os resultados da velocidade específica de crescimento dos fungos, dos 
teores de $\beta$-glucanas e $\mathrm{pH}$ foram submetidos à Análise de Variância (ANOVA) e Teste de Tukey (entre os tratamentos para o mesmo fungo) e teste $t$ (entre os fungos para o mesmo tratamento) a um nível de $5 \%$ de significância para a comparação das médias.

\section{Resultados}

O RCP coletado e utilizado neste estudo apresenta aspecto turvo e de coloração amarelo característico, conforme mostrado na Figura 1.

Relativo à composição do resíduo, os dados obtidos da análise do RCP para os parâmetros da resolução n. 430 (CONAMA, 2011) são apresentados na Tabela 1.

O RCP é caracterizado como sendo Classe II A conforme a NBR 10.004 (ABNT, 2004). A maioria dos parâmetros analisados estão dentro do intervalo de referência e abaixo dos limites impostos pela resolução $n$. 430 (CONAMA, 2011).

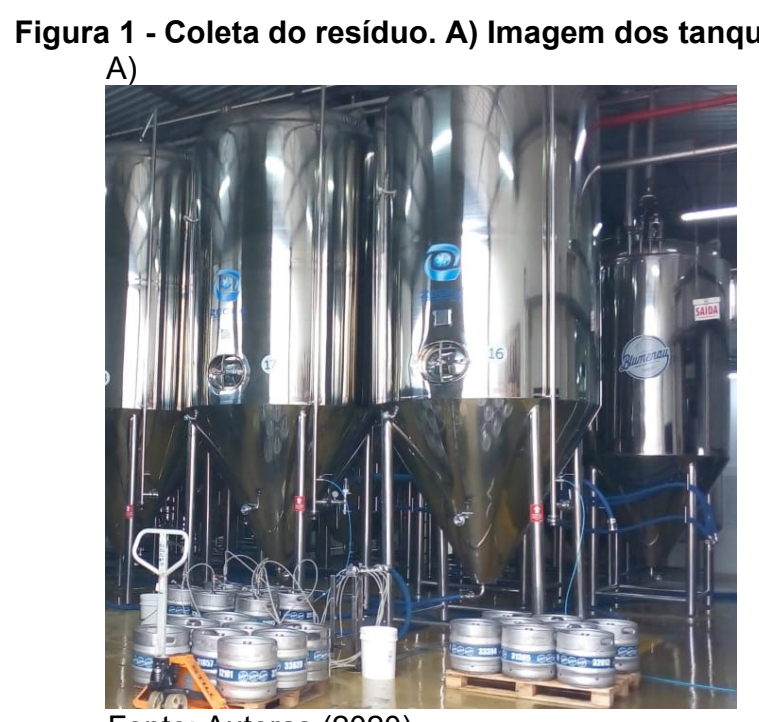

Fonte: Autoras (2020)

Estes elementos e os demais componentes químicos dos efluentes de cervejaria variam, principalmente, conforme as condições operacionais, processos de fabricação e tipo de cerveja (SELUY; ISLA, 2014). O tipo de processo de fabricação também é responsável por quantidades significativas de resíduos com elevada carga orgânica, cuja demanda química de oxigênio (DQO) pode exceder os padrões legais de lançamento. Em termos de DQO, devido a presença de etanol, glicerol e carboidratos remanescentes no efluente de cervejaria, pode apresentar valores da ordem de 170.000 mg.L-1 (SELUY; ISLA, 2014). Nesta pesquisa o efluente indicou DQO igual a $32.050,00 \mathrm{mg}$ $\mathrm{O}_{2} \mathrm{~L}^{-1}$ (Tabela 1), sendo que o valor máximo de referência deste parâmetro é de $120 \mathrm{mg}$ $\mathrm{L}^{-1}$, segundo a resolução n. 430 (CONAMA, 2011).

O parâmetro de demanda bioquímica de oxigênio (DBO) indicou valores de $17.750,00 \mathrm{mg} \mathrm{O}_{2} \mathrm{~L}^{-1}$ (Tabela 1). O valor encontrado para esse efluente excede aos padrões permitidos. No entanto, dada as características nutricionais desse resíduo que

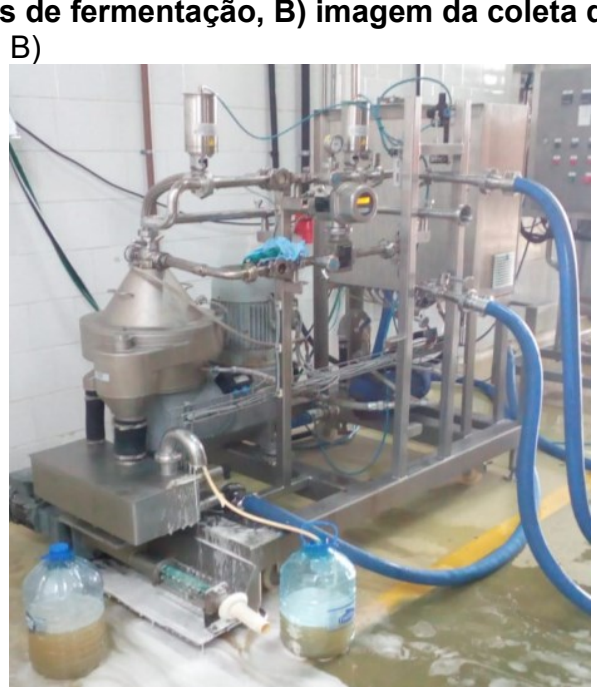

provêm do processo de transformação do malte em cerveja (WISNIEWSKI et al., 2010), este mostra potencial para uso como substrato para cultivo de fungos comestíveis e medicinais.

Os parâmetros de nitrogênio amoniacal, nitrato e nitrito podem atuar como fonte de nitrogênio. $O$ nitrogênio é um elemento de suma importância, pois é constituinte das proteínas, ácidos nucléicos, aminoácidos, enzimas e coenzimas necessárias para $\mathrm{O}$ crescimento $\mathrm{e}$ funcionamento da célula (MACHADO et al., 2012). Neste trabalho o nitrogênio amoniacal do $R C P$ indicou que o valor obtido $\left(9,18 \mathrm{mg} \mathrm{L}^{-}\right.$ 1) foi inferior a praticamente a metade do limite máximo $\left(20 \mathrm{mg} \mathrm{L}^{-1}\right)$ permitido pela legislação que dispõe sobre as condições e padrões de lançamento de efluentes (CONAMA, 2011). Para o parâmetro nitrato, o valor obtido foi de $5,89 \mathrm{mg} \mathrm{L}^{-1}$ e para o nitrito foi de $0,59 \mathrm{mg} \mathrm{L}^{-1}$. Muitos microrganismos mostram grande diversidade na sua utilização destes compostos nitrogenados. Cutrim et al., (2006) estudaram 0 efeito do nitrogênio sobre o desenvolvimento de isolados do fungo 
Penicillium sclerotigenum. Das diversas fontes testadas, o nitrato de sódio foi o menos favorável ao crescimento micelial. No entanto, estudos conduzidos por Jayasinghe et al.
(2008) com oito linhagens de G. lucidum, obtiveram crescimento micelial ótimo em nitrato de cálcio.

Tabela 1 - Valores dos parâmetros caracterizados em $R C P$

\begin{tabular}{lcc}
\hline \multicolumn{1}{c}{ Parâmetros } & Resultados & Unidade \\
\hline Boro & 0,445 & $\mathrm{mg} \mathrm{L}^{-1}$ \\
Cobre Dissolvido & 0,019 & $\mathrm{mg} \mathrm{L}^{-1}$ \\
Cor Real & 651,90 & $\mathrm{Pt} / \mathrm{Co}$ \\
DBO & $17.750,00$ & $\mathrm{mg}^{\circ} \mathrm{O}_{2} \mathrm{~L}^{-1}$ \\
DQO & $32.050,00$ & $\mathrm{mg}^{-\mathrm{O}_{2} \mathrm{~L}^{-1}}$ \\
Ferro Dissolvido & $<0,050$ & $\mathrm{mg} \mathrm{L}^{-1}$ \\
Fósforo & 81,200 & $\mathrm{mg} \mathrm{L}^{-1}$ \\
Manganês Dissolvido & $<0,050$ & $\mathrm{mg} \mathrm{L}^{-1}$ \\
Níquel & $<0,010$ & $\mathrm{mg} \mathrm{L}^{-1}$ \\
Nitrato & 5,89 & $\mathrm{mg} \mathrm{L}^{-1}$ \\
Nitrito & 0,59 & $\mathrm{mg} \mathrm{L}^{-1}$ \\
Nitrogênio Amoniacal & 9,18 & $\mathrm{mg} \mathrm{L}^{-1}$ \\
pH & 4,37 & --- \\
Turbidez & 166,00 & $\mathrm{NTU}^{-1}$ \\
\hline
\end{tabular}

Fonte: Autoras (2020)

Quanto ao parâmetro fósforo $(P)$, considerado elemento essencial à vida, ele é requerido pelos fungos para a síntese de ácidos nucléicos e fosfolipídios. O fósforo também é parte integrante das moléculas de DNA e RNA, e participa dos processos de reprodução e transmissão dos caracteres genéticos (TSAl; ROSSETTO,1992). No $R C P$, o teor em fósforo foi de $81,20 \mathrm{mg} \mathrm{L}^{-1}$. Para meios de cultivo, o fósforo disponibilizado, usualmente, é na forma de fosfato $\left(\mathrm{PO}_{4}{ }^{3-}\right)$. Em estudos de obtenção de exopolissacarídeos (EPS) por G. lucidum, duas concentrações de fosfato na forma de $\mathrm{KH}_{2} \mathrm{PO}_{4}\left(1,0\right.$ a $\left.6,0 \mathrm{~g} \mathrm{~L}^{-1}\right)$ foram testadas (YUAN; CHI; ZHANG, 2012). Os resultados da pesquisa sugerem que o fosfato teve efeito promotor na síntese de EPS e a concentração adequada foi de $2,0 \mathrm{~g} \mathrm{~L}^{-1}$ de $\mathrm{KH}_{2} \mathrm{PO}_{4}$. No entanto, o excesso de fosfato teve efeito negativo no acúmulo de EPS.

Outros parâmetros avaliados no efluente foram o manganês (Mn), cobre (Cu), ferro (Fe), boro (B) e níquel (Ni) que são elementos que também são componentes de diversos meios de cultivo. Estes elementos são considerados micronutrientes requeridos por alguns microrganismos, devido a função exercida. O boro é autoindutor para comunicação célula-célula, enquanto o cobre tem importância na respiração celular. O ferro é cofator para todas as nitrogenases, peroxidases, citocromos, enquanto 0 manganês é ativador de muitas enzimas, além de componente para algumas enzimas superóxido dismutases. O níquel está envolvido com a maioria das hidrogenases (TORTORA; FUNKE; CASE, 2017).

$O$ cultivo de fungos em efluentes é possível, dada a capacidade destes em colonizar e se desenvolver em diferentes resíduos, tais como rejeitos industriais (CHICATTO, 2014) ou lodo de esgoto (MENEZES et al., 2017), pois podem utilizálos como fontes nutricionais para os processos de bioconversão. Para obtenção das $\beta$-glucanas, se faz necessário o uso de meios de cultivo em concentrações adequadas de carbono e nitrogênio, além dos micronutrientes. O equilíbrio de fontes de carbono, nitrogênio, fósforo, vitaminas e micronutrientes fornecido no meio de cultivo é um fator decisivo para o crescimento micelial de fungos (SILVA; MELO, 1999). A utilização do $R C P$ como substrato para a síntese de $\beta$ glucanas por fungos basidiomicetos 
demonstrou-se promissor, pois este contempla diversos componentes nutricionais em sua composição.

Os cultivos fúngicos apresentaram crescimento micelial radial e teores de $\beta$ - glucanas em todos os tratamentos realizados. $\mathrm{Na}$ figura 2, é demonstrado o crescimento micelial radial de $G$. lipsiense e G. applanatum nos diferentes tratamentos após 13 dias de cultivo.

Figura 2 - Características morfológicas das colônias de G. lipsiense e G. applanatum após 13 dias de cultivo

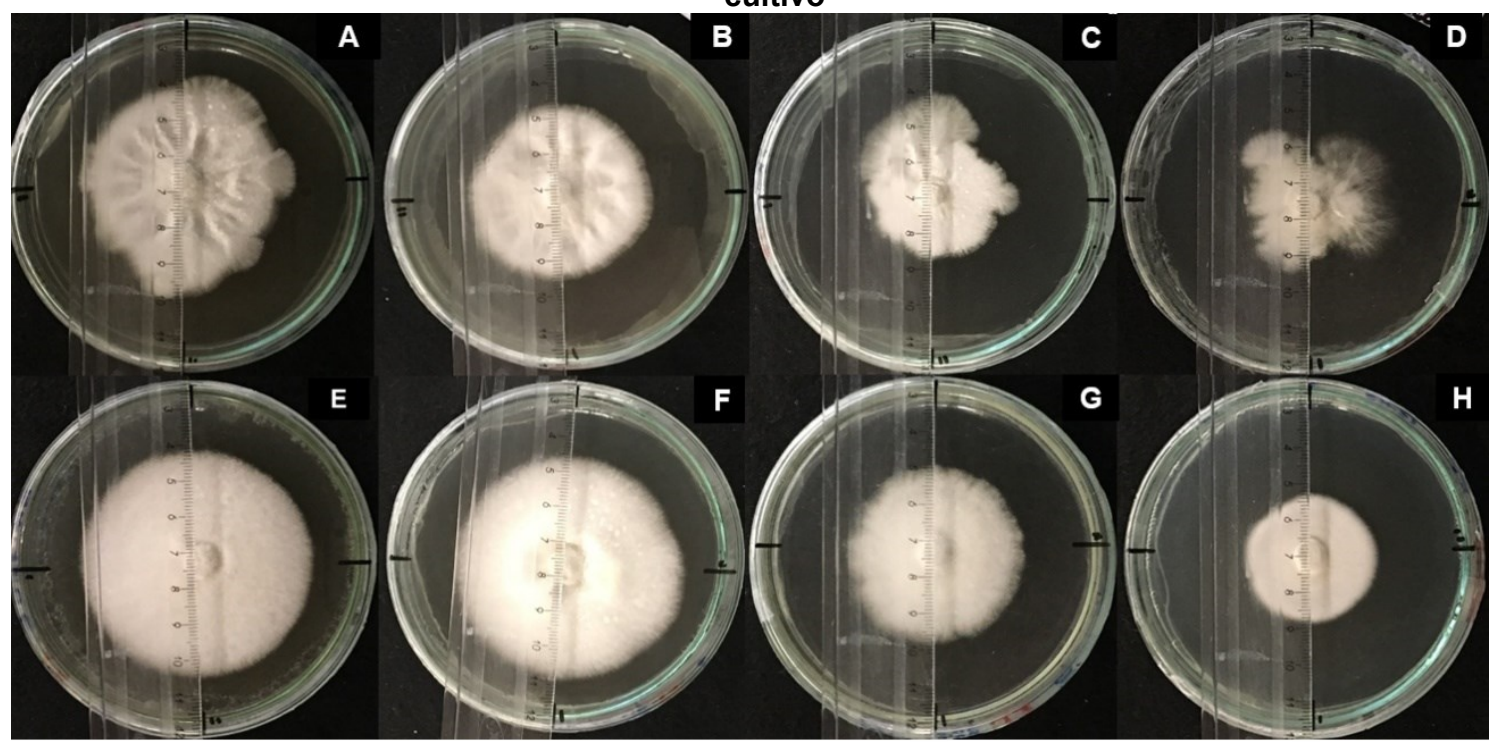

$\mathrm{A}=\mathrm{G}$. lipsiense $(\mathrm{T} 1) ; \mathrm{B}=\mathrm{G}$. lipsiense $(\mathrm{T} 2) ; \mathrm{C}=\mathrm{G}$. lipsiense $(\mathrm{T} 3) ; \mathrm{D}=\mathrm{G}$. lipsiense $(\mathrm{TC}) ; \mathrm{E}=\mathrm{G}$. applanatum (T1); $\mathrm{F}=\mathrm{G}$. applanatum (T2); $\mathrm{G}=\mathrm{G}$. applanatum (T3); $\mathrm{H}=\mathrm{G}$. applanatum (TC). TC = meio sintético BDA; T1 = BDA $(1,5 \% \mathrm{~m} / \mathrm{v})$ e RCP bruto; T2 = BDA $(1,5 \% \mathrm{~m} / \mathrm{v})$ e RCP diluído $50 \%$ em água destilada (50:50); T3 = BDA $(1,5 \%$ $\mathrm{m} / \mathrm{v}$ ) e $R C P$ diluído $75 \%$ em água destilada (25:75).

Fonte: Autoras (2020)

Os valores da $V_{m}$ e da velocidade específica máxima de crescimento $\left(\mu_{\max }\right)$ dos fungos $G$. lipsiense e $G$. applanatum estudados nos distintos tratamentos estão disponibilizados na Tabela 2. O desenvolvimento micelial foi observado em todas as placas, com maiores valores de $V_{m}$ $\left(4,48 \mathrm{~mm} \mathrm{dia}^{-1}\right.$ e $\left.3,90 \mathrm{~mm} \mathrm{dia}^{-1}\right)$ para os fungos $G$. applanatum e $G$. lipsiense, respectivamente, em $\mathrm{T} 1$, no qual continha $\mathrm{o}$ resíduo bruto acrescido de BDA (1,5\%). No entanto, não houve diferença significativa ( $p \leq$ $0,05)$ quanto aos valores de $\mu_{\max }$ para $G$. lipsiense dentre os tratamentos avaliados (Tabela 2), inclusive quando comparado ao TC, no qual apresentou uma diferença de 32,7 \% em relação à T1. O meio BDA é constituído de dextrose (20 $\left.\mathrm{g} \mathrm{L}^{-1}\right)$; infusão a partir de batatas $\left(200 \mathrm{~g} \mathrm{~L}^{-1}\right)$ e Ágar bacteriológico (15 g $\left.\mathrm{L}^{-1}\right)$. Este é um meio a base de fontes de carbono, e que serve como material energético para o desenvolvimento das hifas. $\mathrm{Em}$ todos os tratamentos a mesma concentração em BDA foi utilizada, portanto, o diferencial para aumentar a velocidade de crescimento micelial foram os componentes do efluente $R C P$, listados na Tabela 1 , que atuaram como nutrientes favorecendo a expansão das hifas.

O perfil cinético dos fungos disponibilizado na Figura 3 , indica que o aumento da concentração do RCP proporcionou indução no crescimento das hifas, mas não necessariamente em $\mu$. $O$ fungo $G$. lipsiense apresentou $\mu_{\max } \mathrm{de}$ crescimento (Figura $3 \mathrm{~B}$ ) quando utilizado RCP bruto após 100 horas de cultivo. Para este fungo, a influência da concentração foi nitidamente observada. Já para o fungo $G$. applanatum, embora tenha sido obtido aumento do diâmetro das colônias em meio com maiores concentrações de resíduo (Figura 2), ao longo das 336 horas de cultivo, $\mu$ foi similar nos tratamentos controle e 1 (TC e T1) (Figura 3 A). 
v.22, n. 2, p.32-42, jul./dez. 2020

Tabela 2 - Velocidade média $\left(\mathrm{V}_{\mathrm{m}}\right)$ de crescimento micelial $\left(\mathrm{mm} \mathrm{dia}^{-1}\right)$ e velocidade específica máxima de crescimento $\left(\mu_{\max }\right)$ de G. lipsiense e G. applanatum em $R C P$

\begin{tabular}{|c|c|c|c|c|}
\hline \multirow{2}{*}{ Espécie } & \multicolumn{3}{|c|}{$V_{m}\left(m m d i a^{-1}\right)$} & \multirow[b]{2}{*}{ T3 } \\
\hline & $\mathrm{TC}$ & T1 & $\mathrm{T} 2$ & \\
\hline G. lipsiense & $2,64^{\mathrm{aA}} \pm 0,80$ & $3,90^{\mathrm{aB}} \pm 0,50$ & $3,38^{\mathrm{aA}} \pm 0,45$ & $3,17^{\mathrm{aA}} \pm 0,58$ \\
\hline G. applanatum & $2,99^{\mathrm{bA}} \pm 0,48$ & $4,48^{\mathrm{aA}} \pm 0,19$ & $3,56^{\mathrm{bA}} \pm 0,69$ & $3,11^{\mathrm{bA}} \pm 0,19$ \\
\hline \multicolumn{5}{|c|}{$\mu_{\max }\left(h^{-1}\right)$} \\
\hline G. lipsiense & $0,004^{\mathrm{bB}} \pm 0,002$ & $0,0260^{\mathrm{aA}} \pm 0,011$ & $0,011^{\mathrm{bA}} \pm 0,005$ & $0,005^{\mathrm{bA}} \pm 0,004$ \\
\hline G. applanatum & $0,015^{\mathrm{aA}} \pm 0,004$ & $0,0133^{\mathrm{aA}} \pm 0,000$ & $0,005^{\mathrm{bA}} \pm 0,002$ & $0,009^{\mathrm{abA}} \pm 0,004$ \\
\hline
\end{tabular}

TC = meio sintético BDA; T1 = BDA $(1,5 \% \mathrm{~m} / \mathrm{v})$ e $R C P$ bruto; $\mathrm{T} 2=\mathrm{BDA}(1,5 \% \mathrm{~m} / \mathrm{v})$ e $R C P$ diluído $50 \%$ em água destilada (50:50); T3 = BDA (1,5\% m/v) e RCP diluído $75 \%$ em água destilada (25:75). Média \pm desvio padrão. Letras minúsculas iguais dentro da mesma linha e separado por fungo denotam que não foram encontradas diferenças significativas a um nível de $5 \%$. Letras maiúsculas iguais na mesma coluna e separado por tratamento denotam que não foram encontradas diferenças significativas a um nível de $5 \%$.

Fonte: Autoras (2020)

Figura 3 - Perfil cinético de crescimento dos fungos G. applanatum (A) e G. lipsiense (B) em RCP
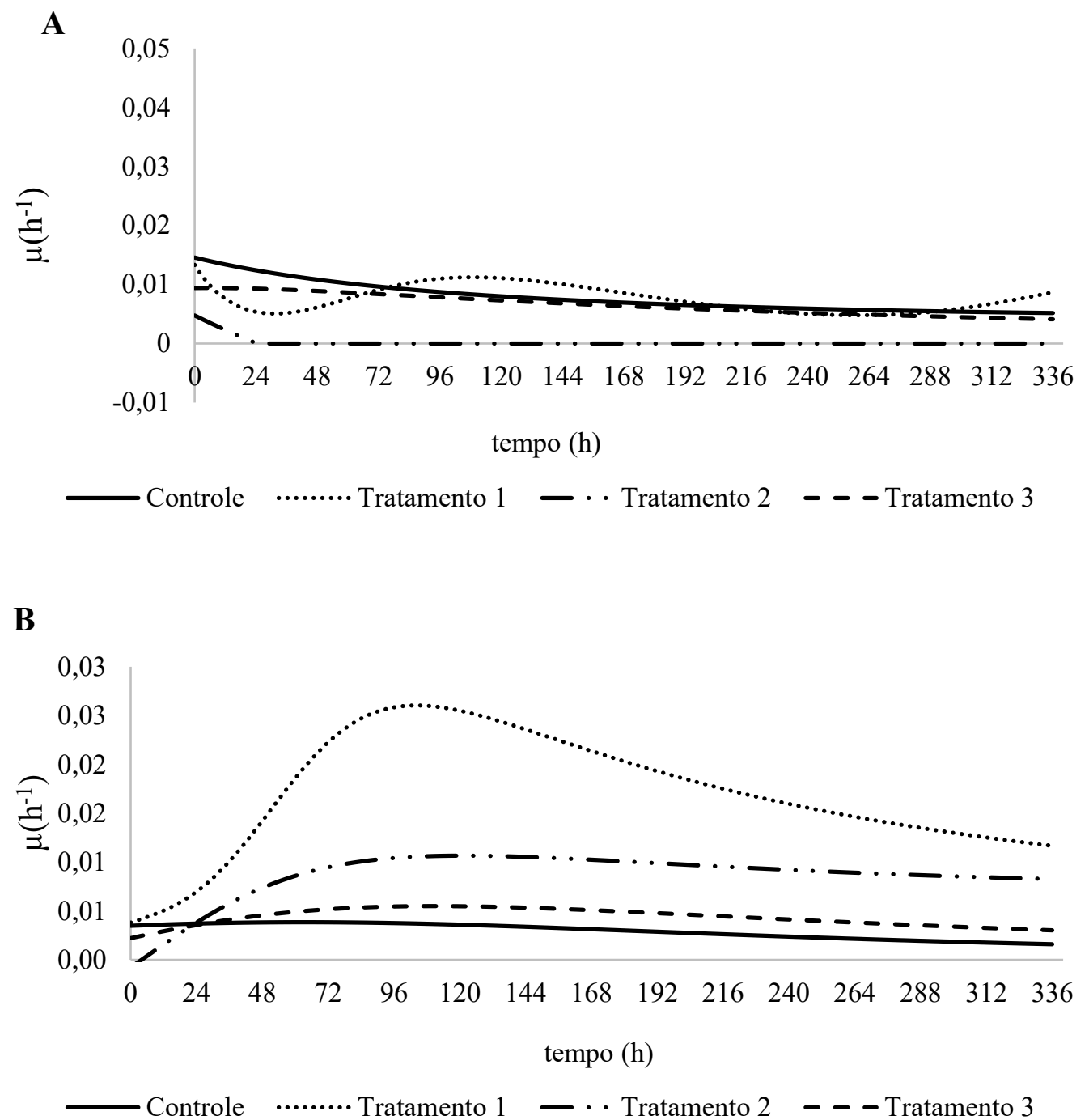

Fonte: Autoras (2020) 
Ambas as cepas G. lipsiense e $G$. applanatum tiveram crescimento micelial superior ao obtido em estudo com 8 linhagens de Ganoderma neo-japonicum (HAFIZAH et al., 2015). Linhagens de G. applanatum cultivadas em meio com glicose ( $\mathrm{JO}$ et al, 2009) apresentaram crescimento similar à linhagem utilizada neste trabalho. No que se refere a $\mu$ (Tabela 2), a partir dos ensaios em placa de Petri, verificou-se que a concentração do resíduo foi fator determinante na velocidade de alongamento das hifas. Para o fungo G. lipsiense, o T1 indicou maior taxa de crescimento, como pode ser visto na Figura 3.

Sais minerais também influenciam no crescimento micelial radial. Diversos sais minerais foram pesquisados em estudo com linhagens de $G$. applanatum por Jo et al. (2009). Foram testados manganês, potássio e zinco na forma de $\mathrm{MgSO}_{4} .7 \mathrm{H}_{2} \mathrm{O}, \mathrm{KH}_{2} \mathrm{PO}_{4}$ e $\mathrm{ZnSO}_{4} .7 \mathrm{H}_{2} \mathrm{O}$, respectivamente. Segundo os autores, os dados de crescimento mostraramse adequados para o manganês e potássio, enquanto zinco resultou em quase nenhum crescimento.

Estes minerais, assim como fosfato (YUAN; CHI; ZHANG, 2012), também são utilizados para a produção de polissacarídeos, por suas propriedades terapêuticas. Os fungos do gênero Ganoderma são amplamente pesquisados quanto a capacidade de produção de moléculas para fins medicinais, como as $\beta$ glucanas (SUPRAMANI et al., 2019). Neste trabalho a produção destas moléculas também foi estudada e os resultados obtidos estão indicados na Figura 4.

Os resultados dos teores de $\beta$ glucanas indicam que os fungos testados têm capacidade de expressão desse polissacarídeo, independente da presença do resíduo de cervejaria. $O$ fungo $G$. lipsiense teve resposta mais favorável a síntese de $\beta$ glucanas, com percentuais superiores ao $G$. applanatum, em todos os tratamentos estudados. G. lipsiense, com teores de $32 \%$ no T2 no qual continha RCP diluído $50 \%$ e $30,28 \%$ no T1 no qual continha RCP bruto. Portanto, o efluente $R C P$ influenciou positivamente na produção do composto, com valores significativamente diferentes $(p \leq$ $0,05)$ para o TC quando comparado aos demais tratamentos com maiores concentrações de $R C P$.

Os resultados apontaram que a velocidade de crescimento micelial radial não é proporcional a produção de metabólitos de interesse farmacêutico, tais como as $\beta$ glucanas, visto que a espécie $G$. lipsiense, a qual apresentou menor velocidade de crescimento micelial, foi a que apresentou maiores teores desse polissacarídeo. Essa é uma característica observada em alguns fungos produtores de bioativos (VIEIRA et al., 2008).

Figura 4 - Teores (\%) de $\beta$-glucanas produzidos por G. lipsiense e G. applanatum

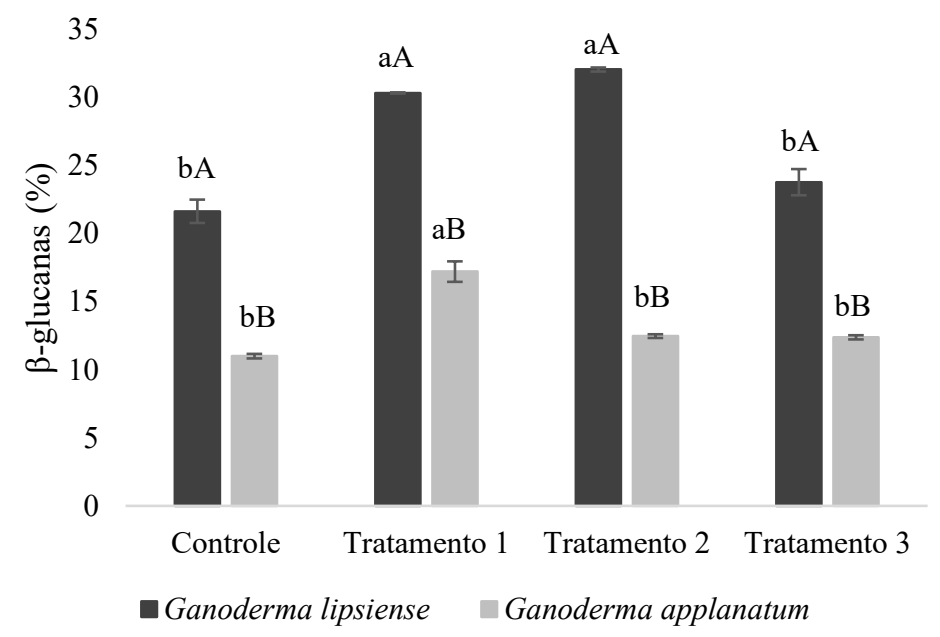

Média \pm desvio padrão. Letras minúsculas iguais para o mesmo fungo denotam que não foram encontradas diferenças significativas a um nível de $5 \%$. Letras maiúsculas iguais para o mesmo experimento denotam que não foram encontradas diferenças significativas a um nível de $5 \%$.

Fonte: Autoras (2020) 
Os valores de $\beta$-glucanas obtidos pelo fungo $G$. lipsiense em $R C P$ foram superiores aos obtidos por Timm et al. (2019) para o fungo Lentinula edodes $(23,65 \%)$. Também em fungos basidiomicetos, Bach, Helm e Haminiuk (2017) relataram a presença de valores de $\beta$-glucanas entre 29,74 e 56,28 $\%$, corroborando com os valores obtidos neste estudo.

$\mathrm{O} \mathrm{pH}$ é outro fator relevante na síntese de moléculas produzidas por fungos. Neste estudo, observou-se que nos tratamentos contendo $R C P$, o $\mathrm{pH}$ final indicou elevação (Tabela 3). O mesmo não foi observado no TC, onde o contrário foi verificado. Algumas espécies de basidiomicetos possuem a capacidade de autorregular seu pH, estabilizando-o a fim de proporcionar seu crescimento ótimo, independentemente do valor de $\mathrm{pH}$ inicial (VIEIRA et al., 2008). A manutenção do pH resulta em melhores respostas enzimáticas, $\mathrm{O}$ que impede a desidratação das hifas e promove uma regulação da concentração de glucose extracelular (CORRADI DA SILVA et al., 2006). No que se refere aos valores, Costa (2019) obteve dados similares de $\mathrm{pH}$, tanto para G. lipsiense como para $G$. applanatum em extratos fúngicos, após 40 dias de cultivo em meio com arroz.

Tabela 3 - Valores de pH dos meios de cultivo para G. applanatum e G.lipsiense

\begin{tabular}{|c|c|c|c|c|c|c|c|c|}
\hline \multirow{3}{*}{ Espécie } & \multicolumn{8}{|c|}{$\mathrm{pH}$ do meio de cultivo } \\
\hline & \multicolumn{2}{|c|}{$\mathrm{TC}$} & \multicolumn{2}{|c|}{ T1 } & \multicolumn{2}{|c|}{$\mathrm{T} 2$} & \multicolumn{2}{|c|}{ T3 } \\
\hline & Inicial & Final & Inicial & Final & Inicial & Final & Inicial & Final \\
\hline G. lipsiense & $\begin{array}{c}5,09^{\mathrm{aA}} \pm \\
0,02\end{array}$ & $\begin{array}{c}4,78^{\mathrm{bA}} \pm \\
0,06\end{array}$ & $\begin{array}{c}4,82^{\mathrm{bA}_{ \pm}} \\
0,02\end{array}$ & $\begin{array}{c}5,39^{\mathrm{aA}} \pm \\
0,07\end{array}$ & $\begin{array}{c}4,92^{\mathrm{bA}} \pm \\
0,03\end{array}$ & $\begin{array}{c}5,23^{\mathrm{aA}} \pm \\
0,14\end{array}$ & $\begin{array}{c}4,99^{\mathrm{bA}} \pm \\
0,02\end{array}$ & $\begin{array}{c}6,28^{\mathrm{aA}} \pm \\
0,14\end{array}$ \\
\hline G. applanatum & $\begin{array}{c}5,09^{a A_{ \pm}} \\
0,02\end{array}$ & $\begin{array}{c}4,93^{\mathrm{bA}} \pm \\
0,08\end{array}$ & $\begin{array}{c}4,82^{\mathrm{bA}} \pm \\
0,02\end{array}$ & $\begin{array}{c}5,14^{\mathrm{aA}}{ }_{ \pm} \\
0,06\end{array}$ & $\begin{array}{c}4,92^{\mathrm{aA}} \pm \\
0,03\end{array}$ & $\begin{array}{c}4,98^{\mathrm{aB}_{ \pm}} \\
0,05\end{array}$ & $\begin{array}{c}4,99^{a} \pm \\
0,02\end{array}$ & $\begin{array}{c}5,08^{\mathrm{aA}} \pm \\
0,14\end{array}$ \\
\hline
\end{tabular}

sintético BDA: T1 = BDA $(1,5 \% \mathrm{~m} / \mathrm{v})$ e $R C P$ bruto; $\mathrm{T} 2=\mathrm{BDA}(1,5 \% \mathrm{~m} / \mathrm{v})$ e $R C P$ diluído $50 \%$ em água destilada (50:50); T3 = BDA (1,5\% m/v) e RCP diluído 75\% em água destilada (25:75). Média \pm desvio padrão. Letras minúsculas iguais dentro da mesma linha e separado por fungo e tratamento denotam que não foram encontradas diferenças significativas a um nível de $5 \%$. Letras maiúsculas iguais na mesma coluna e separado por tratamento denotam que não foram encontradas diferenças significativas a um nível de $5 \%$.

Fonte: Autoras (2020)

\section{Conclusões}

Os resultados mostraram indicativos do potencial do uso do RCP como prática sustentável para uso em processos biológicos para obtenção de compostos de interesse comercial, além de indicar a importância do uso de resíduos de processos industriais como medida de redução de passivos ambientais. Além disso, estudos em placas de Petri são importantes para selecionar, de forma primária, condições de cultivo de fungos que apresentam potencial de crescimento em meios contendo material com distintas composições nutricionais.
Análises de crescimento micelial radial em placas de Petri e de perfis cinéticos de $G$. lipsiense indicaram melhores performances em meio contendo $R C P$ quando comparado ao TC. Resultados semelhantes foram observados para o teor de $\beta$-glucanas, sendo que as maiores concentrações de resíduo influenciaram positivamente na produção. Isto indica que o $R C P$ pode ser empregado como fonte de nitrogênio para cultivo de fungos e síntese de compostos bioativos ( $\beta$-glucanas, micoproteínas, entre outros).

5 Influence of beer production waste on Ganoderma fungi growth and on $\beta$-glucans production

Abstract: The use of beer sector effluents as a substrate in fungal cultivation becomes a sustainable alternative for waste reuse. This work evaluated the speed of radial mycelial growth $(\mathrm{Vm})$ and the production of $\beta$-glucans by the fungi Ganoderma lipsiense and Ganoderma applanatum grown in Petri dishes containing Pilsen beer centrifugation residue (PCR), previously chemically characterized, in the gross concentrations (T1), diluted $50 \%$ (T2) and 75\% (T3), with daily radial measurements for 13 days. At the end of this period, the mycelium was 
removed and subsequently dried $\left(55^{\circ} \mathrm{C}\right)$ to quantify $\beta$-glucans. The chemical characterization of the waste indicated the presence of phosphorus (81.20 mg L-1), ammoniacal nitrogen $\left(9.18 \mathrm{mg} \mathrm{L}^{-1}\right), B O D(17.750,00 \mathrm{mg}$ $\left.\mathrm{O}_{2} \mathrm{~L}^{-1}\right)$, and $\mathrm{COD}$ (32.050, $\left.00 \mathrm{mg} \mathrm{O}_{2} \mathrm{~L}^{-1}\right)$. All waste concentrations provided mycelial growth and production of $\beta$-glucans. At T1, higher Vm (4.48 and $\left.3.90 \mathrm{~mm} \mathrm{dia}^{-1}\right)$ were obtained for $\mathrm{G}$. applanatum and $\mathrm{G}$. lipsiense. Concerning $\beta$-glucans, G. lipsiense presented higher levels (32\%) in T2 and $30.28 \%$ in T1, while G. applanatum produced levels below $20 \%$. The results show the influence of the culture medium concentration and the fungal species on the biocompounds production and suggest that the studied RCP can be reused, being used as a substrate for the compounds production with pharmaceutical interest, such as $\beta$-glucans.

Keywords: Basidiomycete fungi; $\beta$-glucans; Brewing industry.

\section{Referências}

AMERICAN PUBLIC HEALTH ASSOCIATION (APHA). Standard Methods for the Examination of Water and Wastewater. 22th ed. Washington: American Public Health Works Association; 2012.

ASSOCIAÇÃO BRASILEIRA DE NORMAS TÉCNICAS (ABNT). NBR 10.004: Resíduos sólidos - Classificação. 2 ed. Rio de Janeiro, 2004, $71 \mathrm{p}$.

BACH, F.; HELM, C. V.; HAMINIUK, C. W. I. Edible mushrooms: A potential source of essential amino acids, glucans and minerals. International Journal of Food Science \& Technology, v.52, n. 11, p. 2382-2392, 2017.

BENTO, C. B. P.; CASARIL, K. B. P. B. Bioconversão de resíduos agroindustriais ligninocelulósicos por fungos causadores da podridão branca: uma alternativa à produção de alimentos. Revista Faz Ciência, Francisco Beltrão, v. 14, n. 19, p. 151-180, 2012.

CHICATTO, J.A.; CASTAMANN, V. A.; HELM, C.V.; TAVARES, L.B.B. Optimization of the Production Process of Enzymatic Activity of Lentinula edodes (Berk.) Pegler in Holocelulases. Natural Resources, v. 5, p. 241-255, 2014.

CONAMA. Resolução no 430 de 13/05/2011. Conselho Nacional do Meio Ambiente (CONAMA). Dispõe sobre as condições e padrões de lançamento de Diário Oficial da União, Brasília, DF, 16 maio 2011.

CORRADI DA SILVA, M. D. L.; MARTINEZ, P. F.; IZELI, N. L.; SILVA, I. R.; VASCONCELOS, A. F. D.; CARDOSO, M. S.; STELUTTI, R. M.; GIESE, E. C.; BARBOSA, A. M. Caracterização química de glucanas fúngicas e suas aplicações biotecnológicas. Quimica Nova, v. 29, n. 1, p. 8592, 2006.

COSTA, T.M. Produção de metabólitos bioativos pelo fungo Ganoderma lipsiense cultivado em arroz vermelho. Tese (Doutorado em Engenharia Química) - Universidade Federal de Santa Catarina. 167 p. 2019.

COSTA, T.M.; HERMANN, K.L.; GARCIA-ROMAN, M.; CURTO VALLE, R.C.S.; TAVARES, L.B.B.
Lipase production by Aspergillus niger grown in different agro-industrial wastes by solid-state fermentation. Braz. J. Chem. Eng., São Paulo, v.34, n.2, 2017.

COSTA, T.M.; TAVARES, L.B.B.; OLIVEIRA, D. Fungi as a source of natural coumarins production. Applied Microbiology and Biotechnology, v. 100, p. 6571-6584, 2016.

CUTRIM, F.A.; OLIVEIRA, M.A.S; DANTAS, S.A.F.; XAVIER SILVA, R.L. Influência de meios de cultura e da interação carbono-nitrogênio no crescimento e esporulação de Penicillium sclerotigenum. Summa phytopathol. vol.32, n.1, 2006.

DI BERNARDO, A. Influência das condições de aplicação de polímeros catiônicos na eficiência da floculação. 253 p. Dissertação (Mestrado) Escola de Engenharia de São Carlos, Universidade de São Paulo, São Carlos, 2000.

FERREIRA, R. H.; VASCONCELOS, M. C. R. L.; JUDICE, V. M. M.; NEVES, J. T. R. Inovação na fabricação de cervejas especiais na região de Belo Horizonte. Perspectivas em Ciência da Informação, v. 16, n. 4, Belo Horizonte. out/dez.2011.

HAFIZAH, N.U.; NOORLIDAH, A.; ANNUAR, M.S.M.; VIKINESWARY, S. Statistical optimisation of radial growth rates of Ganoderma neo-japonicum (KLUM61076) in low cost solid agar plate's medium using full factorial design and central composite design. J. Trop. Agric. and Fd. Sc. v.43, n.1, p. 61 $-72,2015$.

INSTITUTO ADOLFO LUTZ. Normas analíticas do Instituto Adolfo Lutz: Métodos químicos e físicos para análises de alimentos. v. 1, 4 ed. Brasília, 2005.

JAYASINGHE, C.; IMTIAJ, A.; HUR, H.; LEE, G.W.; LEE, T.S.; LEE, U.Y. Favorable culture conditions for mycelial growth of Korean wild strains in Ganoderma lucidum. Mycobiology, vol 36, p.28-33, 2008.

JO, W.S; CHO, Y.J; CHO, D.H.; PARK, S.D., YOO, Y.B.; SEOK, S.J. Culture Conditions for the Mycelial Growth of Ganoderma applanatum. Mycobiology, vol. 37, n. 2, p.94-102, 2009. 
LASZLO, J. A.; SILMAN, R. W.; Cellular automata simulations of fungal growth on solid substrates. Biotechnology Advances, v.11, p.621-633, 1993.

LENZI, J.; COSTA, T.M. ; ALBERTON, A. D.; GOULART, J.A.G.; TAVARES, L. B. B. Medicinal fungi: a source of anti-parasitic secondary metabolites. Applied Microbiology and Biotechnology. v. 102, p. 5791-5810, 2018.

MACEDO, C.F., SIPAÚBA-TAVARES, L.H. Eutrofização e qualidade de água na piscicultura: consequências e recomendações. Bol. Inst. Pesca, São Paulo, 36(2): 149 - 163, 2010.

MACHADO, D.F.M.; PARZIANELLO, F.R.; SILVA, A.C.F.; ANTONIOLLI, Z.I. Trichoderma no Brasil: o fungo e o bioagente. Rev. de Ciências Agrárias, v.35 n.1, p.1-6, 2012.

MATOS LINS, C.I.., VERAS, F.F., MARTINS, D.B.G., FILHO, J.L.L. Utilização de leveduras para a produção de biomassa em extrato de palma forrageira (Opuntia ficus-indica). Scientia Plena, v. 14, n. 5, 2018.

MENEZES, F.P.; BEVILACQUA, C. B.; SULZBACHER, M. A.; ANTONIOLLI, Z. I.; JACQUES, R. J. S. Capacidade dos fungos lignocelulolíticos em degradar polímeros de lodo de esgoto. Revista de Ciências Agrárias, vol. 40, n.3, p. 515-524, 2017.

PEDRI, Z.C. Uso de biomassa lignocelulósica e Lentinula edodes para desenvolvimento de um biocompósito. 2014. 127p. Dissertação (Programa de Pós-Graduação em Engenharia Ambiental) - Fundação Universidade Regional de Blumenau, Blumenau, 2014

SARI, M, PRANGE, A, LELLEY, J I, HAMBITZER, $R$, Screening of beta-glucan contents in commercially cultivated and wild mushrooms. Food Chemistry 216, 45-51. 2017.

SELUY, L.G.; ISLA, M.A. A process to treat highstrength brewery wastewater via ethanol recovery and vinasse fermentation. Ind. Eng. Chem. Res., v. 53, n. 44, p. $17043-17050,2014$.

SILVA, C.M.M.S.; MELO, I.S. Requisitos nutricionais para o fungo Alternaria. Pesq. agropec. bras., Brasília, v.34, n.3, p.499-503, 1999.

SINGDEVSACHAN, S K, PATRA, J K, TAYUNG, $\mathrm{K}$, THATOI, $\mathrm{H}$, Chemical constituents, antioxidative and antibacterial properties of medicinal mushrooms collected from Similipal Biosphere Reserve, Odisha, India. Proceedings of the National Academy of Sciences, India Section B: Biological Sciences, v.87, n.2, p.559-570, 2017.
SUPRAMANI, S.; AHMAD, R.; WAN-MOHTAR, W.A.A.Q.I. Beta-Glucan from the mycelium of Malaysian medicinal mushroom Ganoderma lucidum and their antimicrobial activities: A potential functional food material. 2nd International Food Research Conference. 299303. 2019.

SOUZA, L.S.T, GUDIÑA, E., RODRIGUES, L., SCHWAN, R.F., DIAS, D.R., TEIXEIRA, J.A. Avaliação da produção de biossurfactantes por espécies de leveduras. Ciência \& Tecnologia. FATC-JB. Número Especial. Jaboticabal, v. 8, 2016.

TIMM, T.G; PASKO, R.Z.; SALES-CAMPOS, C.; HELM, C.V.; TAVARES, L. B. B. Drying process of Lentinula edodes: Influence of temperature on $\beta$ glucan content and. Ciência e Agrotecnologia, v. 43, p. 1-12, 2019.

TORTORA, G.J.; FUNKE, B.R.; CASE, C.L. Microbiologia. 12. ed. Porto Alegre: Artmed, 2017.

TSAI, S.M; ROSSETTO, R. Transformações microbianas do fosfato. Capítulo 17. In: Microbiologia do solo. 360 p. 1992.

VIEIRA, G.R.T.; LIEBL, M.; TAVARES, L.B.B.; PAULERT, R.; SMÂNIA JR. A. Submerged culture conditions for the production of mycelial biomass and antimicrobial metabolites by Polyporus tricholoma Mont. Brazilian Journal of Microbiology, v.39, p. 561-568, 2008.

WHEELER, K. A.; HURDMAN, B. F.; PITT, J. I. Influence of $\mathrm{pH}$ on the growth of some toxigenic species of Aspergillus, Penicillium and Fusarium, International Journal of Food Microbiology, v.12, p.141-150, 1991.

WISNIEWSKI, A. C.; DE ALMEIDA, M. Â. L.; PALMA, M. B.; TAVARES, L. B. B. Produção de enzimas amilolíticas por Macrocybe titans em resíduo do processamento de cerveja. Revista Brasileira de Biociências, v.8, n.3, p.285-293, 2010.

YUAN B.; $\mathrm{CHI}$ X.; ZHANG R. Optimization of exopolysaccharides production from a novel strain of Ganoderma lucidum CAU5501 in submerged culture. Brazilian Journal of Microbiology, p.490497, 2012.

ZENNI, R. S.; HELM, C. V.; TAVARES, L. B. B. Cascas do processamento de palmito para uso na alimentação humana: uma abordagem socioambiental. Revista Gestão \& Sustentabilidade Ambiental, Florianópolis, v.7, n.2, p.276-299, 2018. 